\title{
Why Does Extracellular Potassium Rise in Acute Ischemia? Insights from Computational Simulations
}

\author{
Ana González-Ascaso ${ }^{1}$, Patricia Olcina ${ }^{1}$, Mireia Garcia-Daras ${ }^{1}$, \\ Jose F Rodriguez-Matas ${ }^{2}$, Jose M Ferrero ${ }^{1}$ \\ ${ }^{1}$ Universitat Politècnica de Valencia, Valencia, Spain \\ ${ }^{2}$ Politecnico di Milano, Milano, Italy
}

\begin{abstract}
Hyperkalemia, acidosis and hypoxia are the three main components of acute myocardial ischemia. In particular, the increase of extracellular $K^{+}$concentration (hyperkalemia), has been proved to be very proarrhythmic because it sets the stage for ventricular fibrillation. However, the intimate mechanisms remain partially unknown. The aim of this work was to investigate, using computational simulation, the relationship between the different phases of hiperkalemia, the activity of the ion channels and the changes related to the action potential in the absence of coronary flow. Our results show that the partial inhibition of the sodium-potassium pump is the main cause of extracellular potassium accumulation. However, the cause of the plateau phase could be due to the appearance of action potential alternans, which reduces the net potassium efflux and limits the increase of extracellular potassium concentration.
\end{abstract}

\section{Introduction}

The lack of oxygen and glucose after the interruption of coronary flow in a cardiac tissue provokes metabolic stress. Consequently, the changes in ionic concentrations, in particular the extracellular potassium accumulation, has remarkable consequences on the bioelectric behaviour of the myocytes. It is known that this particular mechanism is strongly related to electrophysiological changes that have been proved to be in the origin of re-entrant arrythmias [1]. In other words, there exists a close relationship between the value of extracellular potassium concentration $\left(\left[\mathrm{K}^{+}\right]_{\mathrm{o}}\right)$ and the occurrence of potentially lethal arrythmias.

Since this phenomenon has a high clinical relevance, several research groups have tried to study its causes. Their results show a temporal evolution of $\left[\mathrm{K}^{+}\right]_{\mathrm{o}}$ characterized by three phases: a first increase during 10-15 minutes from its normoxic value $(3,5-5 \mathrm{mmol} / \mathrm{L})$ to $10-15 \mathrm{mmol} / \mathrm{L}[2,3]$, followed by a stabilization (plateau) and a posterior slower second rise.
However, the causes which explain the evolution of the concentration of the potassium ion in the extracellular environment after the onset of acute myocardial ischemia, are still partially unknown. The aim of this study is to investigate the causes of this triphasic time course of $\left[\mathrm{K}^{+}\right]_{0}$. using computational simulations.

\section{Methods}

A modified version of the model developed by O'Hara et al. [4], which reproduces the electrical behaviour of a human cardiac ventricular myocyte, was used in the simulations to investigate the causes of hiperkalemia in an isolated cardiomyocyte.

To achieve this aim, modifications related to the dynamics and initial and final concentrations of the parameters which change during acute ischemia $\left([\mathrm{ATP}]_{\mathrm{i}}\right.$ [5], [ADP $]_{\mathrm{i}}[6,7,8], \mathrm{pH}_{\mathrm{i}}[5], \mathrm{pH}_{\mathrm{o}}$ and [LPC] $\left.[9,10]\right)$ were introduced based on experimental and computational studies.

Some factors describing how the different ischemic parameters affect some ionic currents, have been formulated and introduced in the model too, including the effect of $\mathrm{pH}_{\mathrm{i}}$ and $\mathrm{pH}_{\mathrm{o}}$ on $\mathrm{I}_{\mathrm{CaL}}$ [11], how the $\mathrm{Na}^{+} / \mathrm{Ca}^{2+}$ exchanger is affected by $\mathrm{pH}_{\mathrm{i}}[12,13]$ and how $[\mathrm{ATP}]_{\mathrm{i}}$ affects $\mathrm{Na}^{+} / \mathrm{K}^{+}$pump [8]. The metabolite Lysophosphatidylcholine (LPC), a lipid formed by the hydrolysis of the membrane phospholipid phosphatidyl choline during myocardial ischemia, has been also introduced in the model because it is thought that its increment affects the fast and late sodium currents $[9,10$, 14].

To determine the effect of specific currents $\left(\mathrm{I}_{\mathrm{KATP}}, \mathrm{I}_{\mathrm{NaK}}\right.$, $\mathrm{I}_{\mathrm{SERCA}}, \mathrm{I}_{\mathrm{Na}}, \mathrm{I}_{\mathrm{NaL}}$ and $\mathrm{I}_{\mathrm{CaL}}$ ) on the accumulation of extracellular potassium, some simulations where only one current behaved ischemic-ly and the others behave normally were carried out.

The model used in the simulations considers the following compartments: the intracellular space, the interstitial extracellular clefts and a bulk extracellular medium in which concentrations were assumed to be 
constant. The following equation simulates the dynamic changes in the extracellular concentration of each ionic specie $\left([S]_{o}\right)[15]$

$$
\frac{d[S]_{o}}{d t}=-\frac{A_{m}}{V_{o} \cdot F} I_{S, t o t}-\frac{[S]_{o}-[S]_{b u l k}}{\tau_{d i f f}}
$$

where $\mathrm{F}$ is the Faraday constant, $V_{o}$ is the extracellular volume, $A_{m}$ the area of the myocyte and $I_{S, t o t}$ is the total ionic current related to ion $\mathrm{S}$. In the second term $\tau_{\text {diff }}$ in the time constant for the diffusion of $\mathrm{S}$ and $[S]_{o}$ and $[S]_{\text {bulk }}$ are the concentrations of the ion in the extracellular space and in the bulk, respectively.

The stimulation period (BCL) was $1000 \mathrm{~ms}$ (that corresponds to a frequency of $60 \mathrm{bpm}$ ). The virtual myocyte was paced for 20 minutes, during which the ischemic parameters were varied according to experimental recordings [5-10]. The system of differential equations was solved using the finite differences method using Matlab ${ }^{\circledR}$.

\section{Results and Discussion}

Using the model as described in Methods section, we simulated the time course of $\left[\mathrm{K}^{+}\right]_{\mathrm{o}}$ during 20 minutes of dynamically-changing ischemia (black curve, Figure 1). This time course nicely agrees with experimental results $[2,6]$.

To further investigate the causes of cellular $\mathrm{K}^{+}$loss during ischemia, the role of different ionic currents was analyzed. For this purpose, we carried out additional simulations in which one current at a time was kept "ischemic" (i.e. affected by the dynamic changes of ischemic metabolites) while the others maintained a normoxic behavior. Figure 1 shows the time courses of $\left[\mathrm{K}^{+}\right]_{\mathrm{o}}$ that correspond to these additional simulations.

The results show that the progressive inhibition of the $\mathrm{Na}^{+} / \mathrm{K}^{+}$pump accounts for most of the $\mathrm{K}^{+}$accumulation (red curve), while the time course of $\left[\mathrm{K}^{+}\right]_{\text {o }}$ shows similar tendencies when the ATP dependant potassium current ( $\mathrm{I}_{\mathrm{K}(\mathrm{ATP})}$, blue curve), the late sodium current ( $\mathrm{I}_{\mathrm{NaL}}$, red curve) and the SERCA pump (purple curve) are kept ischemic.

The contributions of the different ionic currents affected by ischemia have not yet been completely elucidated from experiments $[2,16]$. Our simulations suggest that the partial inhibition of the $\mathrm{Na}^{+} / \mathrm{K}^{+}$pump plays a major role in the ischemic increase of $\left[\mathrm{K}^{+}\right]_{\mathrm{o}}$. Conversely, the progressive activation of $\mathrm{K}_{\mathrm{ATP}}$ channels that enhances $\mathrm{K}^{+}$efflux and hence extracellular potassium accumulation plays a much smaller role in the extracellular $\mathrm{K}^{+}$concentration time course. A possible explanation of this small effect is that the opening of the $\mathrm{K}_{\text {ATP }}$ channels not only increase $\mathrm{K}^{+}$ efflux but also provokes a faster repolarization of the action potential, leading to a shortening in the duration of the action potential and a decrease of the time during which other potassium currents are activated.

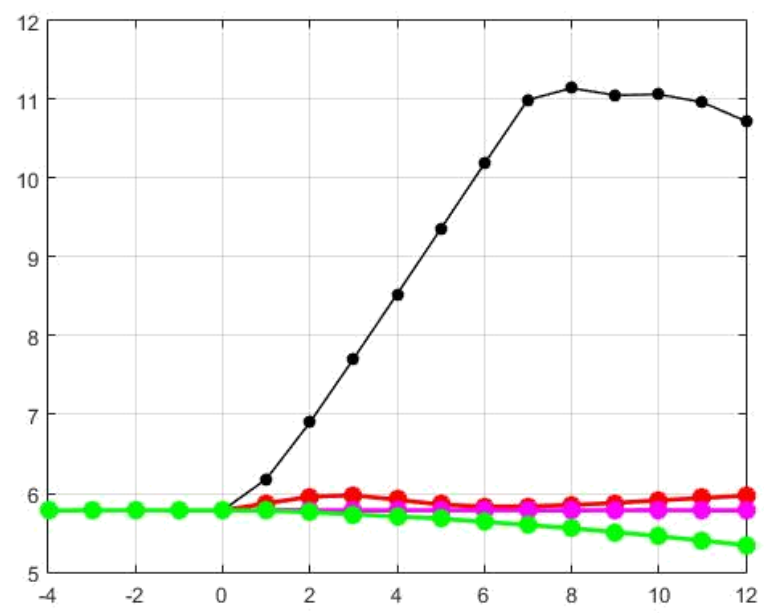

Figure 1. Time course of extracellular $\mathrm{K}^{+}$concentration under different simulation conditions. See text for details.

Other experimental evidences have suggested that the alternation of $\mathrm{Na}^{+}$fluxes [17] could contribute to the accumulation of potassium outside the cell due to the enhancement of $\mathrm{K}^{+}$driving force and $\mathrm{K}^{+}$efflux [18] when the $\left[\mathrm{Na}^{+}\right]_{i}$ increases. Our results suggest that the single activation of $\mathrm{I}_{\mathrm{NaL}}$ is not sufficient to increase the value of the extracellular potassium concentration significantly.

The next question that we aimed to answer using the model was the cause of the plateau in $\left[\mathrm{K}^{+}\right]_{\mathrm{o}}$. The results of our model show that the stabilization of extracellular potassium is concomitant with the sudden appearance of alternating action potentials. Figure 2 depicts the time course of membrane potential during specific intervals of the ischemic event corresponding to different phases of the accumulation of extracellular potassium. During normoxia (Figure 2A) and the first 6 minutes of the absence of coronary flow (four consecutive action potentials corresponding to the fourth minute of ischemia are shown in Figure 2B), which corresponds to the rising phase of $\left[\mathrm{K}^{+}\right]_{0}$, the morphology of consecutive action potentials does not change (i.e. no alternating action potentials can be observed). However, when reaching the potassium plateau (eighth minute of ischemia, see Figure 2C), the pattern of the action potentials changes and alternans appear. This phenomenon is further shown in Figure 2D, in which the time course of action potential duration at $90 \%$ of repolarization $\left(\mathrm{ADP}_{90}\right)$ is shown. The curve shows a bifurcation from the 7-8 minute of the ischemic event onwards, corresponding to the existence of alternating action potentials.

According to our simulations, the appearance of action potential alternans could be the cause of the plateau phase in extracellular potassium accumulation. The explanation of this relationship could be that the alternation in action 
potential duration limits the potassium efflux, leading to a stabilization in the accumulation of potassium in the extracellular environment.
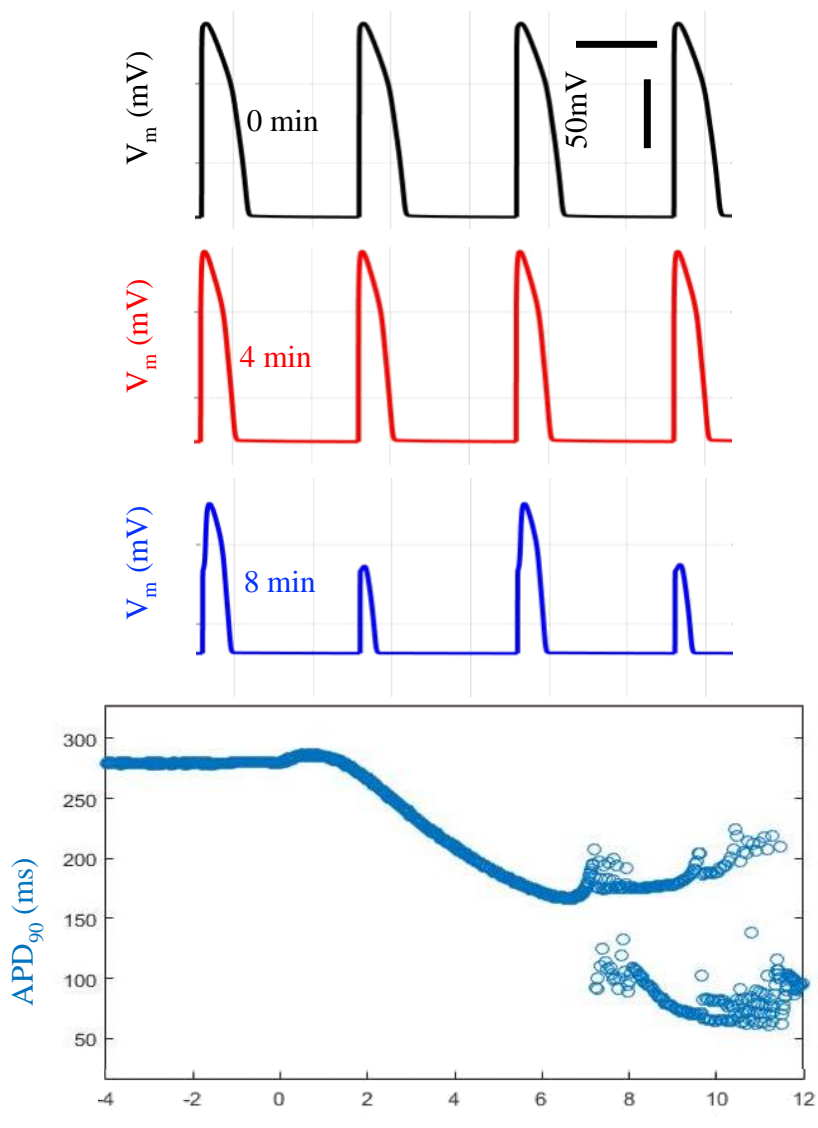

Figure 2. A-C: Four consecutive action potentials before the onset of ischemia (A) and after 4 (B) and 8 (C) minutes of acute ischemia. $\mathrm{D}$ : $\mathrm{ADP}_{90}$ evolution during the first 12 minutes acute of myocardial ischemia.

\section{Conclusions}

Our results show that the partial inhibition of the sodium-potassium pump is the main cause of extracellular potassium accumulation. However, the cause of the plateau phase could be due to the appearance of action potential alternans, which reduces the net potassium efflux and limits the increase of extracellular potassium concentration.

\section{Acknowledgments}

This work was partially supported by the "Programa Salvador de Madariaga 2018" of the Spanish Ministry of Science, Innovation and Universities (Grant Reference PRX18/00489).

\section{References}

[1] A. S. Harris, A. Bisteri, R. A. Russel, J. C. Brigham and J. E. Firestone, "Excitatory factors in ventricular tachycardia resulting from myocardial ischemia. Potassium a major excitant," Science, vol. 119, pp. 200-103, Feb. 1954.

[2] A. A. Wilde and G. Aksnes, "Myocardial potassium loss and cell depolarisation in ischemia and hypoxia," Cardiovasc. Res., vol. 29, pp. 1-15, Jan. 1995.

[3] M. L. Walker and D. S. Rosenbaum, "Repolarization alternants: implications for the mechanism and prevention of sudden cardiac death," Cardiovasc. Res., vol. 57, no. 3, pp. 599-614, Mar. 2003.

[4] T. O'Hara, L. Virág, A. Varró and Y. Rudy. "Simulation of the undiseased human cardiac ventricular action potential: model formulation and experimental variation," Plos. Comput. Biol., e1002061, May. 2011.

[5] K. Sakamoto, M. Ishikawa, K. Koga, T. Urshidani and T. Nagao, "Energy preserving effect of 1-cis diltiazem in isolated ischemic and Reperfused guinea pig hearts: A 31PNMR Study," Jpn. J. Pharmacol., vol. 83, no. 3, pp. 225232, Jul. 2000.

[6] J. N. Weiss, N. Venkatesh and S. T. Lamp, "ATP-sensitive $\mathrm{K}+$ channels and cellular $\mathrm{K}+$ loss in hypoxic and ischaemic mammalian ventricle," J. Physiol., vol. 441, pp. 649-673, Feb. 1992.

[7] K. Clarke, A. J. O'Connor and R. J. Willis, “Temporal relation between energy metabolism and myocardial function during ischemia and reperfusion," Am. J. Physiol., vol. 253, no.2 part 2, pp. H412-421, Aug. 1987.

[8] J. R. Terkildsen, E. J. Crampin and N. P. Smith, "The balance between inactivation and activation of the $\mathrm{Na}+\mathrm{K}+$ pump underlies the triphasic accumulation of extracellular $\mathrm{K}+$ during myocardial ischemia," Am. J. Physiol. Heart Circ. Physiol., vol. 293, no. 5, pp. H3036-3045, Nov. 2007.

[9] P. Deleau, "Lysophosphatidylcholine, a metabolite which accumulates early in myocardium during ischemia, reduces gap junctional coupling in cardiac cells," J. Mol. Cell. Cardiol., vol. 31, no.7, pp. 1391-1401, Jul. 1999.

[10] M. Gautier, H. Zhang and I. M. Fearon, "Peroxynitrite formation mediates LPC-induced augmentation of cardiac late sodium currents," J. Mol. Cell. Cardiol., vol. 42, no.2, pp. 241-251, Sep. 2007.

[11] N. Saegusa, E. Moorhouse, R. D. Vaughan-Jones and K. W. Spitzer, "Influence of $\mathrm{pH}$ on $\mathrm{Ca} 2+$ current and its control of electrical and $\mathrm{Ca} 2+$ signaling in ventricular myocytes," $J$. Gen. Physiol., vol. 138, no.5, pp. 537-559, Nov. 2011.

[12] S. John, B. Kim, R. Olcese, J. I. Goldhaber and M. Ottolia, "Molecular determinants of $\mathrm{pH}$ regulation in the cardiac $\mathrm{Na}^{+}-\mathrm{Ca}^{2+}$ exchanger," J. Gen. Physiol., vol. 150, no 2, pp. 245-257, Feb. 2018.

[13] A. E. Doering and W. J. Lederer., "The mechanisms by which cytoplasmatic protons inhibit the sodium-calcium exchanger in guinea-pig heart cells," J. Physiol., vol. 466, pp. 481-499, Jul. 1993.

[14] A. I. Undrovinas, I. A. Fleidervish and J. C. Makielski, "Inward sodium current at resting potentials in single cardiac myocytes induced by the ischemic metabolite lysophosphatidylcholine," Circ. Res., vol. 71, no.5, pp. 1231-1342, Nov. 1992.

[15] J. M. Ferrero, J. Sáiz, J. M. Ferrero and N. V. Thakor, "Simulation of action potentials from metabolically impaired 
cardiac myocytes. Role of ATP-sensitive K current," Circ. Res., vol. 68, pp. 208-221, Aug. 1996.

[16] E. Carmeliet, "Cardiac ionic currents and acute ischemia: from channels to arrythmias," Physiol. Rev, vol. 79, pp. 9171017, Jul. 1999.

[17] U. Decking, M. Hartmann, H. Rose, R. Brückner and J. Meil, "Cardioprotective actions of KC12291 I. Inhibition of voltage-gated $\mathrm{Na}+$ channels in ischemia delays myocardial Na+ overload," Naunyn Schemiedebergs Arch. Pharmacol., vol. 358, pp. 547-553, Nov. 1998.
[18] K. Shivkumar, N. A. Deutsch, S. T. Lamp, K. Khuu, J. I. Goldhaber and J. N. Weiss, "Mechanisms of hypoxic K loss in rabbit ventricle," J. Clin. Invest., vol. 100, pp. 1782-1788, Oct. 1997.

Address for correspondence:

Jose M Ferrero

Departamento de Ingeniería Electrónica

Universidad Politécnica de Valencia.

Camino de Vera s/n, 46022 Valencia, Spain

cferrero@ci2b.upv.es 